\title{
SPATIO-TEMPORAL ASSESSMENT OF MARGALLA HILLS FOREST BY USING LANDSAT IMAGERY FOR YEAR 2000 AND 2018
}

\author{
Rida Batool and Kanwal Javaid \\ The University of the Punjab Quaid-E-Azam Campus Lahore, Pakistan - (rida.xehra93, knwl.j92)@gmail.com
}

KEY WORDS: Change Detection, LULC, Supervised Classification, Satellite Remote Sensing, LANDSAT ETM+ and OLI.

\begin{abstract}
:
Environmental imbalance due to human activities has shown serious threat to ecosystem and produced negative impacts. The main goal of this study is to identify, monitor and classify temporal changes of forest cover, build up and open spaces in Margalla Hills National Park, Islamabad. Geographic Information Sciences (GISc) and Remote Sensing (RS) techniques has been used for the assessment of analysis. LANDSAT-7 Enhanced Thematic Mapper (ETM+) and LANDSAT-8 Operational Land Imager (OLI) were utilized for obtaining data of year 2000 and 2018. Temporal changes were evaluated after applying supervised classification and discrimination was analyzed by Per-Pixel based change detection. Results depicts forest cover decrease from $87 \%$ to $74 \%$ whereas build up has increased from 5\% to $7 \%$ over the span. Consequences also justify the presence of open land in study area that has been increased from $2 \%$ to $7 \%$ respectively.
\end{abstract}

\section{INTRODUCTION}

In South Asia, Pakistan is among those countries which has very low biodiversity. It has experienced high rates of deforestation in recent years (World Resource Institute, 1996). Pakistan covers less than $5 \%$ of forest area. One of the major reason of losing forest cover is due to increase in population day by day that has transformed forested area into agricultural land and for built-up purposes. A serious notice has been taken by the Government of Pakistan in recent years over deforestation for significant growth of national parks in different parts of country to conserve biodiversity in their natural habitats. There are many national parks, reserves and wildlife refuges in Pakistan but the problem is of poor management due to insufficient government funds and poor policies with an open access to the visitors.

In Pakistan, there are more than 230 Protected Areas (PAs) which cover almost $11 \%(2,753,357$ hectares $)$ of the country's land. These PAs represent almost every ecological, terrestrial and aquatic ecosystem and are considerably important for their ecological and socio-economic services. The Margalla Hills National Park (MHNP) was declared National Park under the Islamabad wild life ordinance (1979) and established in 1980 (Zafar, 2014). Being capital of country Islamabad is extensively growing and expanding. Roads and buildings are developing and ultimately land use land cover of the city has been changed and will continue to multiply for coming years (Rai et al., 2011).

Many past researchers analyzed various methods for the control and reduction of rapid urbanization within green areas. Though, in this era of modernization assessment and monitoring of land use land cover pattern probe techniques of satellite remote sensing (SRS) and geographic information systems (GIS) globally. Remote Sensing (RS) has provided the opportunity to achieve data and information over the land surface with the help of sensors incorporated with space borne or airborne crafts. These sensors helps to explore earth surface with desired area and specific details. Whereas, GIS helps in mapping those information with their spatial registration and integration of data takes places with both spatial and non-spatial formats for various purposes of vegetation monitoring, identification and classification (Jeyaseelan, 2003).

This research study, land use change dynamics were investigated by the combined technological advancements of SRS and GIS. The Multi-spectral and temporal classification that is Supervised
Classification (Maximum Likelihood) classifies land cover into different classes that comprehends changes and unravel difference (Walter, 2004). LULC detection with supervised classification is considered as the easiest, less time consuming and inexpensive way to determine dynamics of land rather surveys and labor.

In this paper method of 'Per-Pixel Based Change Detection' has been used to understand maximum to minimum change over 18 years of study. Pixel as the fundamental unit of image analysis has spectral significance. This method elaborates, pixels of same Digital Number (DN) reflects similar reflectance from ground, detects and measure changes on the bases of pixels rather spatial content (Hussain et al., 2013). After the detection statistical evaluation of each pixel is done by using technique of 'Image Difference' in GIS. This is an additional way of analysis for detecting change of a particular area of interest. Multi-temporal images of different years (2000 and 2018) were subtracted pixel by pixel to get appropriate results of changes in Margalla Hills.

\section{STUDY AREA}

The study area of this research is Margalla Hills National Park (MHNP) as depicted by Figure 1. MHNP is located in Islamabad North Pakistan. Its geographical coordinates are $33^{\circ} 40^{\prime} 43^{\prime \prime} \mathrm{N}$ latitude, $72^{\circ} 45^{\prime} 01^{\prime \prime}$ to $72^{\circ} 52^{\prime} 32^{\prime \prime} \mathrm{E}$ longitude (Zafar, 2014). Hills of Margalla are strechted from north to north-west around $40 \mathrm{~km}$ in length (Malik \& Hussain, 2003). Margalla Hills along with its rugged, gullies and steepe slopes topography is enriched with chemicals like limestone that is also being detoriate by human activites (Iqbal et al., 2013).

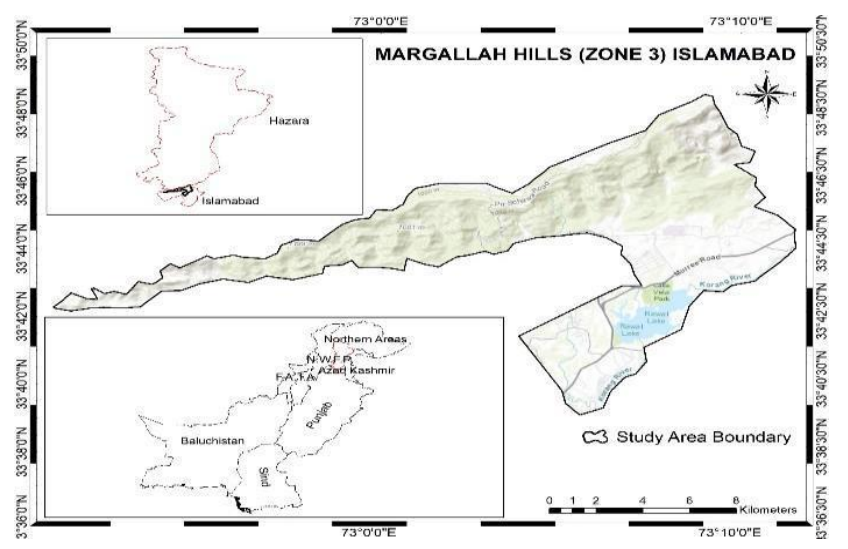

Figure 1: Study Area Margalla Hills National Park (MHNP) Islamabad, Pakistan. 
3

\section{LAND USE LAND COVER (LULC)}

Land use and land cover has a unique relationship on both regional and global scale. Human activities like agricultural, cultivation, grazing animals, settlements, developing roads and building infrastructures are categorized as land use while on the other hand environment, biodiversity, natural cover and ecosystems collectively shared by land cover (Turner et al., 1996).

In RS, image classification is a science that can transform satellite data into meaning full information that explains about land cover and its condition with class of severity. Purpose of image classification is to categorize, interpret and simplification of data (Zhou et al., 2009). In collaboration with SRS, GIS mapping plays very significant role in the identificaton and analysis of LULC in Margalla Hills. It reveals behaviour of natural resource environment and risk degradation.

\subsection{Supervised Classification (Year 2000)}

Supervised classification is a type of classification in which numerical discriminators are made up of those data sets already assigned as a class of their identity for easy identification of larger land covers on land. In this classification, training sites are very significant in identification of pixels inside and outside training areas before the allocation of classes (Zhou \& Wang, 2011). Supervised classification is always considered better than supervised because user is already known with the knowledge of what to classify.

For the estimation of LULC year 2000 five classes were classified as Forest, Open Land, Water bodies, Build up and shadow. Supervised classification (Maximum Likelihood) was applied on LANDSAT-7 ETM+ image for year 2000 ( $7^{\text {th }}$ January) as presented in Figure 2. The analysis exhibit forested area is largest that covers around $496.4897 \mathrm{sq} \mathrm{km}$ area and carries almost $87 \%$ of total Margalla Hills also displayed in Graph 1. Build up shows the second largest area of $40.276 \mathrm{sq} \mathrm{km}$ with 5\% of total Margalla Hills, Open land shares third category with area of $17.2192 \mathrm{sq} \mathrm{km}$ of $2 \%$ total while Water bodies shares area of $3.4777 \mathrm{sq} \mathrm{km}$ and $1 \%$ of total as least area of Margalla Hills.

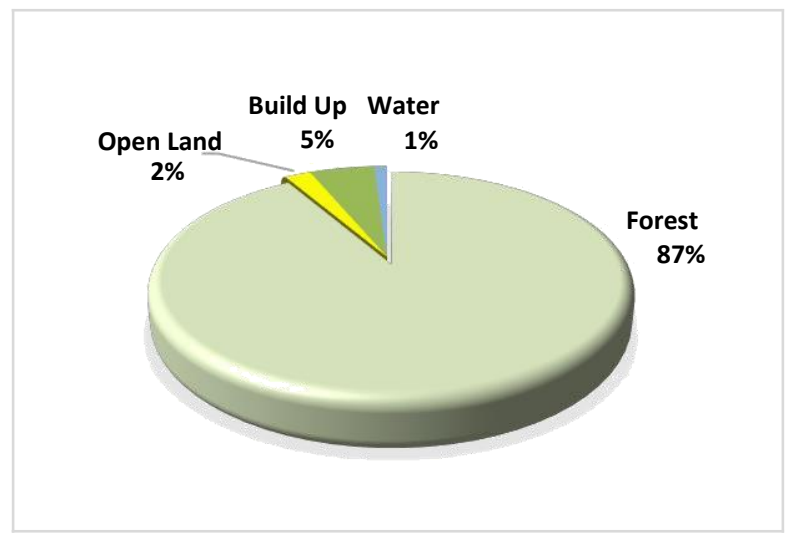

Graph 1: Supervised Classification Area Percentage (\%) Margalla Hills Year 2000.

Summing up, the LULC classification reports forest area are vast in Margalla Hills and smallest cover is of water bodies in year 2000. Environmental conditions under which the supervised classification was performed was calm and free of fog and condensation. Analysis clearly communicate the presence of natural cover in past.

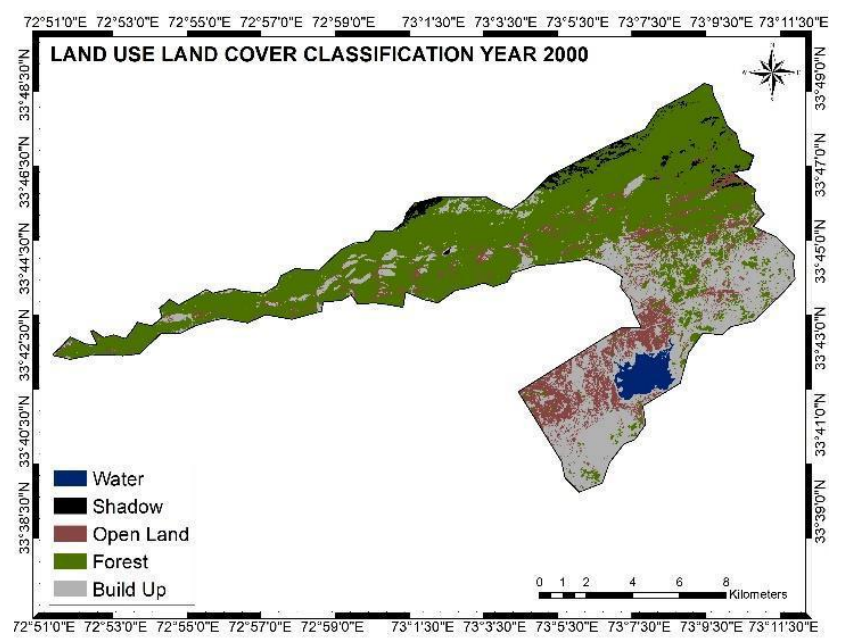

Figure 2: Land Use/ Land Cover Supervised Classification Margalla Hills National Park (MHNP) Year 2000 Islamabad, Pakistan.

\subsection{Supervised Classification (Year 2018)}

For the approximation of LULC for year 2018 similar five classes were selected as Forest, Open Land, Water bodies, Build up and shadow. Supervised classification (Maximum Likelihood) was applied on LANDSAT-8 OLI image for year $2018\left(6^{\text {th }}\right.$ January) as demonstrated in Figure 3.

The temporal analysis with comparison to year 2000 analysis were quite different and changed. As elaborated from Graph 2 forested area covers around $496.4897 \mathrm{sq} \mathrm{km}$ area in year 2000 has been reduced to $4313.416 \mathrm{sq} \mathrm{km}$ or in other words, percentage of forested area has been lessen to $74 \%$ from $87 \%$. Similarly, build-up area has increased its ratio from 5\% to $7 \%$. Open land has also directed an increasing pattern in Margalla Hills with the area of $56.2676 \mathrm{sq} \mathrm{km}$ in current year, the value has been raised from $2 \%$ to $7 \%$ in previous 18 years. Water body has materialized environmental condition during the performance of land use land cover classification for year 2018 .

In Figure 3 as compared to figure 2 estimates increased amount of water because of the weather condition of Islamabad. At that time of data acquisition fog and condensation were experienced in study area. Water has not changed its originality from last 18 years but analysis shows the presence of weather factor affecting water area.

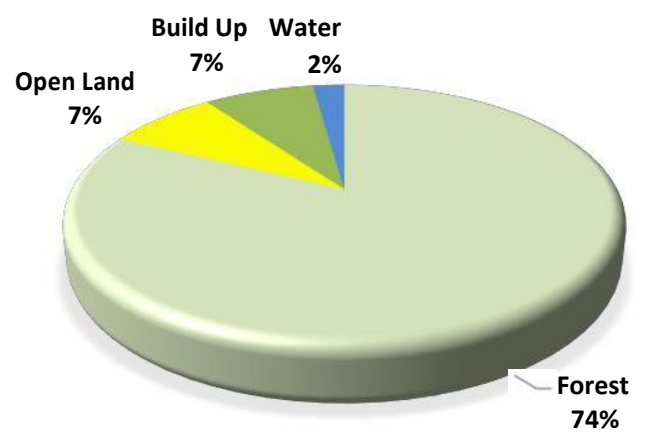

Graph 2: Supervised Classification Area Percentage (\%) Margalla Hills Year 2018. 


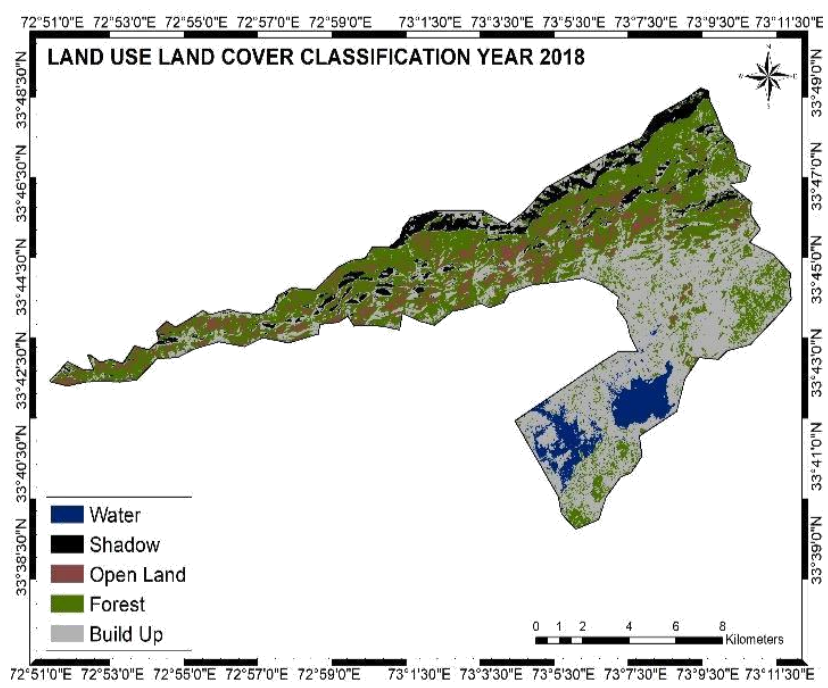

Figure 3: Land Use/ Land Cover Supervised Classification Margalla Hills National Park (MHNP) Year 2018 Islamabad, Pakistan.

As mentioned above, the contrast between LANDSAT images analysis for year 2000 and 2018 observed extensive number of forest area diminution hence, natural park of Margalla Hills is losing its nature. Urban expansion in Islamabad is driving environment therefore, deforestation is discerned. This analysis also conveys that if urban development within the territory of nature keep on increasing than soon more loss of forest and degradation of natural environment will be suffered. The 'shadow' class in this analysis shows relief and elevation of Margalla Hills National Park (MHNP). Methodology used for Supervised Classification along with the applications of GIS has distinctly confirm the changes over the time period of study.

\section{CHANGE DETECTION (CD)}

\subsection{Image Difference}

Assuming the difference of both LANDSAT images for year 2000 (LANDSAT-7 ETM+) and 2018 (LANDSAT-8 OLI) the analysis of 'Image Difference' was applied in context to Change Detection. In this method, both images were first classified by using supervised classification temporally and land use land cover change was identified. After classification, Image Difference was calculated, this technique leads to the subtraction of two spatially registered image pixel by pixel (Song et al., 2001) as shown in Equation 1 and 2.

$$
\begin{aligned}
& D_{i j k}^{\prime}=\left[D N_{i j k}(1)-A k(1)\right]-\left[D N_{i j k}(2)-A k(2)\right], \\
& D_{i j k}=D N_{i j k}(1)-D N_{i j k}(2)=D_{i j k^{\prime}}+C
\end{aligned}
$$

Where,

$\mathrm{D}^{\prime}{ }_{\mathrm{ijk}}=$ Difference Image with Atmospheric condition

$\mathrm{DN}_{\mathrm{ijk}}(1 \& 2)=$ Digital Number $(\mathrm{DN})$ of both images

$A_{k} \quad=$ Additive atmospheric bands

C = Difference Constant

To get change map and desire results threshold boundaries were found between stable and change pixels. Finally change detection map was analyzed as shown in Figure 4.

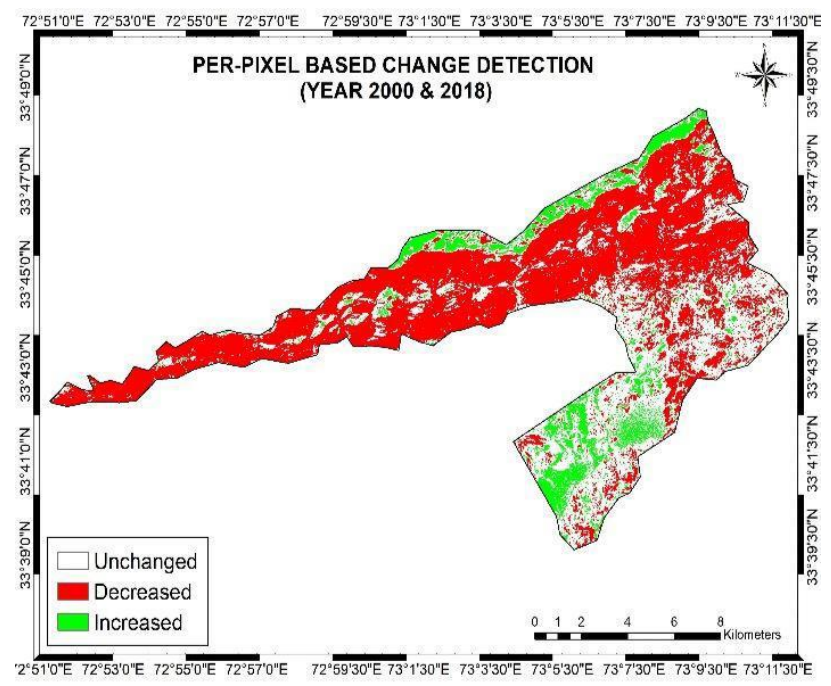

Figure 4: Per-Pixel Based Change Detection by applying Image Difference for year 2000 and 2018, Margalla Hills National Park (MHNP) Islamabad, Pakistan.

From the analysis of per-pixel based change detection results shows that change map has three categories that is Area where change is increased which means that urbanization trend is increased as particularly displayed with green color in Figure 4. Whereas, area where change is decreased shows the forest degradation on risk which means that as compare to year 2000 most of the forest is decreased in 2018. Area with no change are some particular parts found in both urban class and vegetation class.

As illustrated from Figure 4 it has been observed that area of forest has been decreased shown with red color whereas the area of build-up and open spaces has increased their values. This analysis proves that urbanization is taking over the environment, ecosystem, biodiversity and natural habitat of many species. Decrease in forest region has clearly identified the alarming situation for environment detoriation in Margalla Hills National Park (MHNP). If the parameters of deforestation and fast urbanization remain unidentified and monitoring on temporal basis remain unchecked than severe environmental degradation is expected to be experience.

\section{CONCLUSION}

We presented a methodology for the monitoring and identification of Change by using Multi-temporal and Multispatial data of LANDSAT imagery for Margalla Hills National Park (MHNP). Detection begun with the classification and selection of land use land cover categories of MHNP. From analysis it has been concluded that forest coverage area has shown total $14 \%$ of reduction. Urbanization has catalyzed forest detoriation and urban areas are replaced by green areas. Monitoring and identification of change in Margalla Hills National Park (MHNP) is very important in future so that area of forest lost or about to damage should be manage.

It has been demonstrated that Image Difference Per-Pixel Change Detection has shown the area of alarm where forest has been decreased, for future study it is highly recommended to have temporal monitoring and assessment of forest decrease in these particular areas of Margalla Hills. It is also recommended that monitoring should place at least once in a year. 


\section{REFERENCES}

Hussain, M., Chen, D., Cheng, A., Wei, H. and Stanley, D., 2013. Change detection from remotely sensed images: From pixelbased to object-based approaches. ISPRS Journal of Photogrammetry and Remote Sensing, 80, pp.91-106.

Iqbal, M.F., Khan, M.R. and Malik, A.H., 2013. Land use change detection in the limestone exploitation area of Margalla Hills National Park (MHNP), Islamabad, Pakistan using geo-spatial techniques. Journal of Himal. Earth Sc, 46, pp.89-98.

Malik, R.N. and Husain, S.Z., 2003. Evaluating deforestation using Landsat TM and SPOT XS data in dry sub-tropical forest of Margalla Hills, northwest of Pakistan. Geoinformation for European-wide Integration, pp.429-434.

Rai, P.K., Gupta, S., Mishra, A. and Onagh, M., 2011. Multiseasonal IRS-1c LISS III satellite data for change detection analysis and accuracy assessement: a case study. Journal of GIS Trends, 2(1), pp.13-19.

Song, C., Woodcock, C.E., Seto, K.C., Lenney, M.P. and Macomber, S.A., 2001. Classification and change detection using Landsat TM data: When and how to correct atmospheric effects?. Remote sensing of Environment, 75(2), pp.230-244.

Turner, B.L., Meyer, W.B. and Skole, D.L., 1994. Global landuse/land-cover change: towards an integrated study. Ambio. Stockholm, 23(1), pp.91-95.

Walter, V., 2004. Object-based classification of remote sensing data for change detection. ISPRS Journal of photogrammetry and remote sensing, 58(3), pp.225-238.

Zafar, S.M., 2014. Spatio-temporal analysis of land cover/land use changes using geoinformatics (A Case Study of Margallah Hills National Park). Indian Journal of Science and Technology, 7(11), pp.1832-1841.

Zhou, W., Huang, G., Troy, A. and Cadenasso, M.L., 2009. Object-based land cover classification of shaded areas in high spatial resolution imagery of urban areas: A comparison study. Remote Sensing of Environment, 113(8), pp.1769-1777.

Zhou, X. and Wang, Y.C., 2011. Spatial-temporal dynamics of urban green space in response to rapid urbanization and greening policies. Landscape and Urban Planning, 100(3), pp.268-277.

World Resource Institute, 1996, World Resources: A Guide to the Global Environment (The Urban Environment) 1996-97, Oxford and New York: Oxford University Press. 